\title{
Environmental Impacts of Compact Fluorescent Lamps and Linear Fluorescent Lamps in China
}

\author{
Sha Chen ${ }^{1, ~ a ~, ~ J i a x i n g ~ Z h a n g ~}{ }^{2, b}$ \\ ${ }^{1}$ Key Laboratory of Beijing on Regional Air Pollution Control, Environmental \& Energy Engineering \\ College, Beijing University of Technology, Beijing, China \\ ${ }^{2}$ Institute of Recycling Economy, Beijing University of Technology, Beijing, China \\ aemail: shachen68@163.com, bemail: zhangjx29@163.com
}

Keywords: life cycle assessment (LCA); compact fluorescent lamps; linear fluorescent lamp; environmental burden

Abstract. China is one of the largest fluorescent lamps consuming and producing countries in the world. However, there are few studies evaluating environmental impacts of fluorescent lamps in China. This study compared the environmental impacts of two lighting systems in China-compact fluorescent lamps and linear fluorescent lamps - throughout the life cycle. The methodological framework is based on the ISO standards 14040 and 14044. All the materials, energy use and pollutant emissions to the environment from each process were analyzed. The environmental impact was estimated for the 7 environmental impact categories: Abiotic Depletion Potential, Global Warming Potential, Acidification Potential, Eutrophication Potential, Respiratory Inorganics, Waste Solids and Water Use. The results indicated that the environment burden of the products was highest in the use phase due to electricity use. Impact caused by distribution and disposal can be neglected. According to the analyzed environmental impact categories and from an environmental point of view the linear fluorescent lamp is more appropriate source of light than compact fluorescent lamps.

\section{Introduction}

Fluorescent lamps are increasingly being used for general lighting due to their higher energy efficiency than incandescent lamps. It is estimated that lighting consumes about $19 \%$ of the global electricity production, of which about $62 \%$ is consumed by fluorescent lamps (FLs) [1]. In addition, with the phasing out of incandescent lamps in several countries, such as China [2], America and Australia [3], the popularity of FLs is rising. Furthermore, China is one of the largest FLs consuming and producing countries in the world. In 2011, domestic production of compact fluorescent lamps(CFLs) in china accounted for over $80 \%$ of the world's production [4]. Therefore, it is increasingly important to investigate the environmental performance of FLs at Chinese conditions.

So far, a few of studies have been performed to analyze the environmental impacts of FLs using life cycle thinking and methodology. Quirk [5] investigated the full life-cycle costs and benefits of using a $13 \mathrm{~W}$ CFL and $6 \mathrm{~W}$ LED as compared to a less efficient $60 \mathrm{~W}$ incandescent lamp. The study found that CFL and LED lamp were roughly four times more efficient than incandescent lamps. The OSRAM [6] evaluated the environmental impacts of a $40 \mathrm{~W}$ incandescent, $8 \mathrm{~W}$ CFL and $8 \mathrm{~W}$ LED lamp, and it is concluded that current LED lamps, as of 2009, are comparable to CFLs of life-cycle energy, and both provide significant energy savings compared to incandescent lamps. Navigant Consulting Europe Ltd. [7] conducted an LCA comparing a variety of lighting products, including a $12 \mathrm{~W}$ LED, $23 \mathrm{~W}$ CFL. 28 $\mathrm{W}$ linear fluorescent lamp(LFL) and $100 \mathrm{~W}$ incandescent lamp, and determined the environmental impacts to resources, soil, air and water. The United States Department of Energy (DOE) [8] has published reports on the energy analysis and life cycle environmental impacts of associated with a LED and comparing those to a CFL and an incandescent lamp. Most previous studies focus on the comparative of CFLs, LED and incandescent lamps. Previous estimates have found that fluorescent lamps and LED result in a clearly lower environmental impact than incandescent lamps, and the use phase is the main contributor to impacts. However, these studies are not evaluating environmental impacts of FLs considering of Chinese conditions. The use and disposal stages are modelled by the 
developed countries though it is assumed that lamps are produced in China in some analyses. For example, Ramroth [3] provides an evaluation of the environment impacts of 13 Watt CFL and an equivalent 60 Watt incandescent lamp, and it is assumed both lamps were made in China and then shipped to the US. There is an increasing need to analyze the environmental impacts of FLs at Chinese conditions.

This study compares the environmental impacts of compact fluorescent lamps and linear fluorescent lamps from their manufacture to the final disposal phase at Chinese conditions. The goal is to determine the life cycle stages and material and energy inputs that cause the greatest impacts. The results allow for a better understanding of environmental impacts characteristics of FLs and help policy makers and customers take informed decision.

\section{Methods}

Life cycle assessment(LCA) is scientific methodology that enables researchers to quantify and provide a comprehensive view of the environmental impacts of a product across a range of categories for a product over its entire life cycle. The LCA is conducted according to the international standards ISO 14040 (2006) and ISO 14044 (2006) [9,10]. An LCA study is composed of four steps - goal and scope definition, inventory analysis, impact assessment and interpretation.

\section{Goal and scope definition}

The goal of this LCA is to determine which of the two domestic lighting technologies examined has the better environmental performance and investigate the greatest environmental burden over their life cycle stages, material and energy inputs. In addition, how sensitive the environmental impacts are to the life of the luminaire and to the energy mix of the use stage is determined. A cradle to grave approach has been taken up for the study including the manufacturing, distribution, use, and end-of-life stages of the lamps. The life cycle of the four stages is shown in Fig. 1.

The lamps selected were a $15 \mathrm{w}$ CFL and a 28w T5 FL. Functional unit selected for this study was 62 million lumen-hours of lighting service, which is approximately representative of total light output of a 28w T5 FL over its lifetime. And it is equal to 8 times of the CFL to provide light throughout its stated life. EBalance software have been used to model different processes in the life cycle of the two lighting technologies, which is a LCA software developed by China. EcoInvent and Chinese Life Cycle Database(CLCD) Database were used as databases. CLCD is a database based on Chinese conditions, which can be on behalf of the average Chinese market.

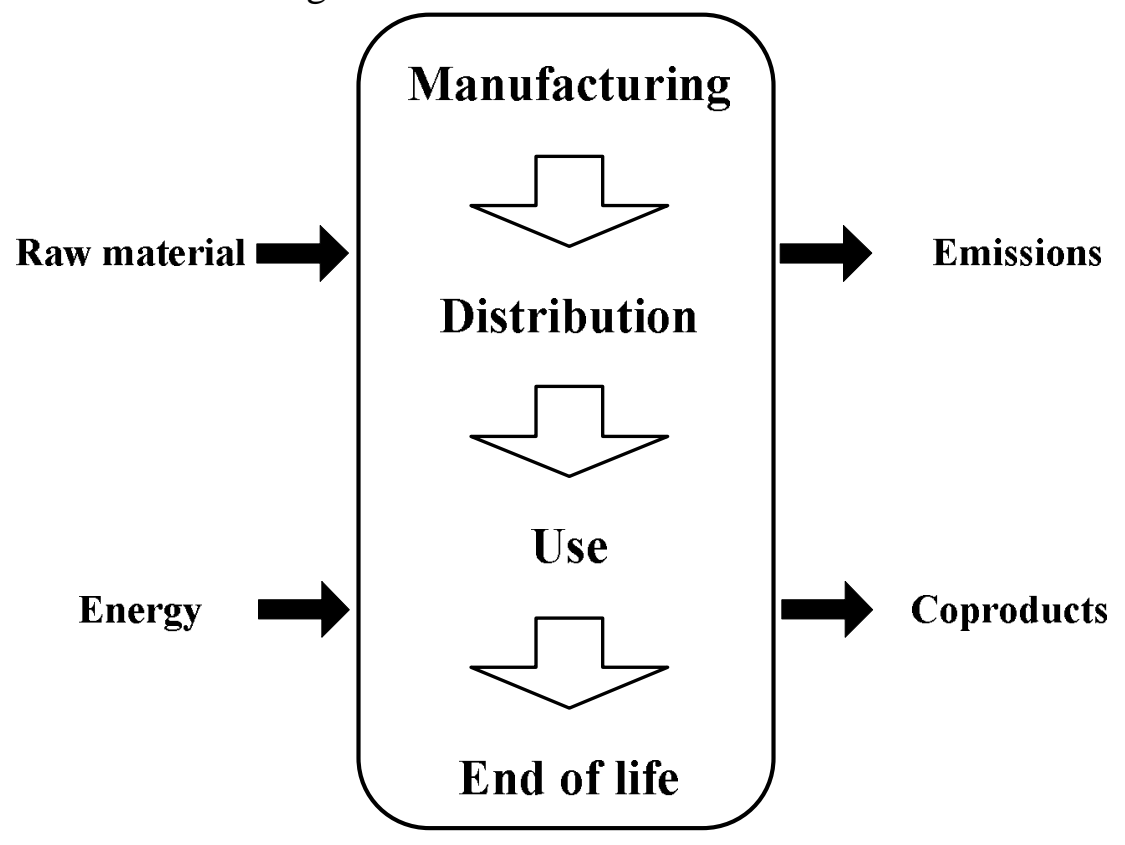

Figure 1 Life-cycle stages of lamps 


\section{Inventory analysis}

During this phase, all flows of the materials, energy and the waste associated with the function unit are identified and quantified.

Raw material production. This stage accounts for the emissions and resource usage associated with the production of the various raw materials that go into the final product and their transportation to the manufacturing point. The data for the inventory analysis were collected from $[7,8]$. The Table 1-2 provide a list of all the raw materials that are assumed used in the CFL and LFL.

Table 1 Raw material inventory for the CFL

\begin{tabular}{lll}
\hline Material & Database & Amount \\
\hline Argon gas & CLCD & $0.004 \mathrm{~g}$ \\
Nitrogen gas & CLCD & $0.119 \mathrm{~g}$ \\
Oxygen gas & CLCD & $0.159 \mathrm{~g}$ \\
Hydrogen gas & CLCD & $0.002 \mathrm{~g}$ \\
Ammonia & CLCD & $0.13 \mathrm{~g}$ \\
Nitric acid & CLCD & $7.9 \mathrm{~g}$ \\
Sulfuric acid & CLCD & $1.67 \mathrm{~g}$ \\
Aluminum Oxide & CLCD & $0.008 \mathrm{~g}$ \\
Lead & CLCD & $0.19 \mathrm{~g}$ \\
Copper & CLCD & $0.402 \mathrm{~g}$ \\
Nickel & CLCD & $0.003 \mathrm{~g}$ \\
Mercury & CLCD & $0.004 \mathrm{~g}$ \\
Natural Gas & CLCD & $10.7 \mathrm{~kg}$ \\
Power & CLCD & $3.13 \mathrm{MJ}$ \\
Neon gas & EcoInvent & $0.0004 \mathrm{~g}$ \\
Noble Earths & EcoInvent & $0.001 \mathrm{~g}$ \\
Yttrium Oxide & EcoInvent & $1.37 \mathrm{~g}$ \\
Brass & EcoInvent & $1.65 \mathrm{~g}$ \\
Cast iron & EcoInvent & $0.029 \mathrm{~g}$ \\
Chromium & EcoInvent & $0.0002 \mathrm{~g}$ \\
Capacitor & EcoInvent & $40 \mathrm{pcs.}$ \\
Coil miniature & EcoInvent & $3 \mathrm{pcs}$. \\
Diode SMD & EcoInvent & $40 \mathrm{pcs.}$ \\
PWB & EcoInvent & $3.7 \mathrm{~g}$ \\
Resistor SMD & EcoInvent & $40 \mathrm{pcs}$. \\
Thermistor, NTC & EcoInvent & $0.19 \mathrm{~g}$ \\
Transistor power large & EcoInvent & $3.70 \mathrm{~g}$ \\
Resin Glue & EcoInvent & $4.5 \mathrm{~g}$ \\
Solder paste & EcoInvent & $0.3 \mathrm{~g}$ \\
Glass Tube & EcoInvent & $1.20 \mathrm{~g}$ \\
Housing top \& bottom (PBTP) & $2.39 \mathrm{~g}$ \\
Packaging & EcoInvent & $81 \mathrm{~g}$ \\
\hline
\end{tabular}


Table 2 Raw material inventory for the LFL

\begin{tabular}{lll}
\hline Material & Database & Amount \\
\hline Glass & CLCD & $194.29 \mathrm{~g}$ \\
Caps & CLCD & $6.3 \mathrm{~g}$ \\
Wiring & CLCD & $0.557 \mathrm{~g}$ \\
Sockets & CLCD & $5 \mathrm{~g}$ \\
Coil & CLCD & $43.4 \mathrm{~g}$ \\
Metal Film Capacitor & CLCD & $4.65 \mathrm{~g}$ \\
ELKO Component & CLCD & $3.1 \mathrm{~g}$ \\
Luster Terminal(polypropylene) & CLCD & $2.325 \mathrm{~g}$ \\
Gases(argon) & CLCD & $2.1 \mathrm{~g}$ \\
Mercury & CLCD & $0.01 \mathrm{~g}$ \\
Packaging(Plastic) & CLCD & $10 \mathrm{~g}$ \\
Phosphor & EcoInvent & $4.2 \mathrm{~g}$ \\
Gases(krypton) & EcoInvent & $2.1 \mathrm{~g}$ \\
Base & EcoInvent & $500 \mathrm{~g}$ \\
PCB & EcoInvent & $15.5 \mathrm{~g}$ \\
Housing & EcoInvent & $79.05 \mathrm{~g}$ \\
PET Film & EcoInvent & $3.1 \mathrm{~g}$ \\
Solder Paste & EcoInvent & $1.55 \mathrm{~g}$ \\
Luster Terminal(steel) & EcoInvent & $2.325 \mathrm{~g}$ \\
Polycarbonate & EcoInvent & $1010 \mathrm{~g}$ \\
Packaging(Card) & EcoInvent & $4.11 \mathrm{~g}$ \\
Sheet rolling, aluminium & EcoInvent & $14.05 \mathrm{~g}$ \\
Steel product manufacturing, average metal working & EcoInvent & $500 \mathrm{~g}$ \\
Wire drawing, copper & EcoInvent & $0.56 \mathrm{~g}$ \\
Injection moulding & EcoInvent & $1017.3 \mathrm{~g}$ \\
Sheet rolling, chromium steel & EcoInvent & $81.38 \mathrm{~g}$ \\
Extrusion, plastic film & EcoInvent & $13.1 \mathrm{~g}$ \\
Aluminium product manufacturing, average metal working & EcoInvent & $43.4 \mathrm{~g}$ \\
\hline
\end{tabular}

Most of the FL manufacturers have located in the southeast provinces, such as Zhejiang, Guangdong and Jiangsu accounting for more than $87 \%$ of the production in China [11]. Therefore, the electricity generation during the production was chosen as the mix of southeast in China.

Manufacturing. The manufacturing phase takes all of the raw materials defined above, as delivered to the point of production, and accounts for the energies used and emissions associated with fabricating the final product. The manufacturing activities are based on the assembly of LCD screen.

Distribution. Distribution stage includes the transport from the manufacturer site to the place it is used, and it is estimated to be $1,800 \mathrm{~km}$ by lorry within China. In addition, packaging is taken into account. For the CFL, the lamp itself weighs $153 \mathrm{~g}$ and the card-stock packaging was measured at 81 $\mathrm{g}$, taken together the lamp inside the box totals approximately $234 \mathrm{~g}$ [8]. For the LFL, the lamp weighs about $1.88 \mathrm{~kg}$ and taken with the packaging is $1.895 \mathrm{~kg}$ [7].

Use. It is assumed that there is no diminishing performance during the lifetimes of lamps, so the power consumption and light emitted per watt are constant. It is also assumed that the luminaire systems would be powered by average Chinese electricity.

End of life. In the end-of-life phase detailed processes for disposal, recycling and landfill as municipal solid waste are taken into account. Waste management of spent FLs has not received sufficient attention in China, and most of spent FLs are discarded as household waste. The available data on FLs recycling in China is absence and China is a developing country, so the recycling rate is assumed and applied as 5\% [12]. The remaining FLs are assumed to be disposed to be landfilled. In 
addition to the lamps itself, the fate of its packaging is also considered. $80 \%$ of cardboard boxes are assumed to be recycled, and the other $20 \%$ landfilled.

\section{Impact assessment}

The environmental impact is estimated for the 7 environmental impact categories, are provided in Table 3.

Table 3 The indicators for the selected environmental impact categories

\begin{tabular}{ll}
\hline Environmental impact category & Category indicator \\
\hline Abiotic Depletion Potential(ADP) & $\mathrm{Kg}$ antimony-eq \\
Global Warming Potential (GWP) & $\mathrm{Kg} \mathrm{CO}_{2}$-eq \\
Acidification Potential (AP) & $\mathrm{Kg} \mathrm{SO}_{2}$-eq \\
Eutrophication Potential (EP) & $\mathrm{Kg} \mathrm{PO}_{4}$-eq \\
Respiratory Inorganics(RI) & $\mathrm{Kg} \mathrm{PM}{ }_{2.5}$-eq \\
Waste Solids & $\mathrm{Kg}$ \\
Water Use & $\mathrm{Kg}$ \\
\hline
\end{tabular}

\section{Results and discussion}

Table 4 Life cycle assessment results of the CFL

\begin{tabular}{llllllll}
\hline LCA stages & ADP & AP & EP & GWP & RI & Waste Solids & Water Use \\
\hline Raw material & 0.0188098 & 0.47984 & 0.55309 & 24.27605 & 0.06685 & 0.01666 & 0.62657 \\
Manufacturing & 0.0000473 & 0.01050 & 0.00763 & 1.24168 & 0.00156 & 0.00000 & 0.01947 \\
Distribution & 0.0000003 & 0.00046 & 0.00008 & 0.04342 & 0.00009 & 0.00057 & 0.11456 \\
Use & 0.0000767 & 0.63681 & 0.04205 & 120.24245 & 0.18604 & 23.11548 & 402.79504 \\
End of life & 0.0000002 & 0.00019 & 0.00021 & 0.08913 & 0.00004 & 0.00000 & 1.33003 \\
Total & 0.0189342 & 1.12780 & 0.60305 & 145.89273 & 0.25458 & 23.13272 & 404.88567 \\
\hline
\end{tabular}

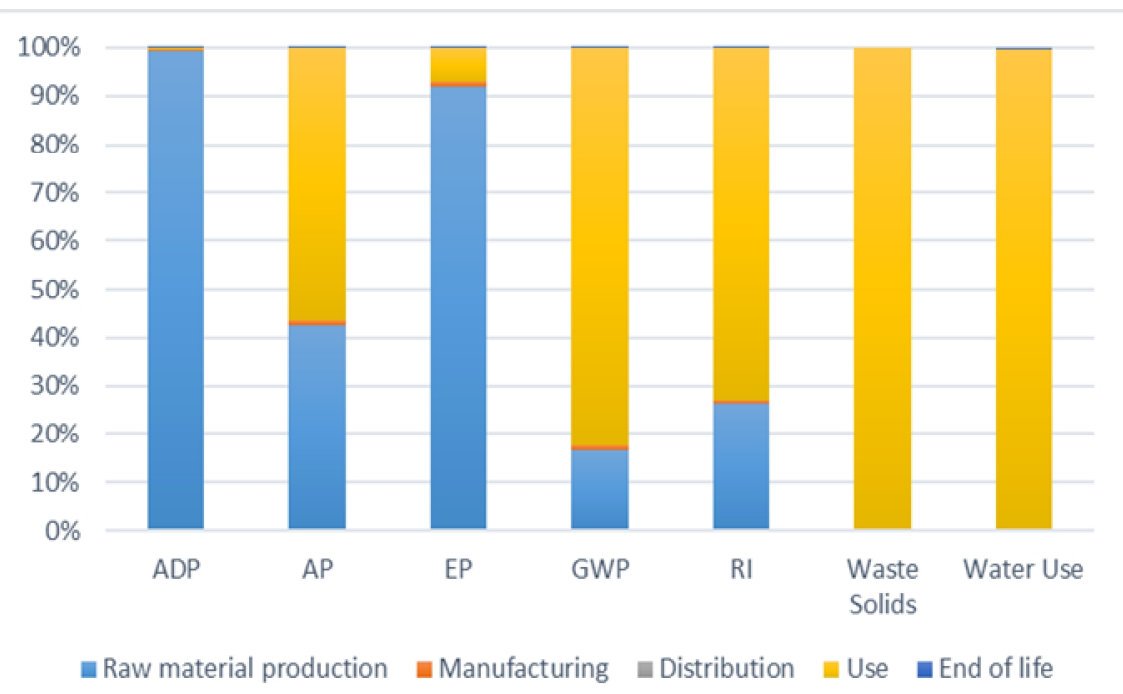

Fig. 2 Proportions of the life cycle assessment results for the CFL

As is presented in Table 4 and Fig. 2, the proportion of impact attributable to energy in use is particularly high for the CFL, except for the ADP and EP, of the other impacts energy in use constitutes more than $50 \%$ over the lifetime of the lamp. The next most significant stage of the assessment is the raw materials, especially in GWP and EP, accounting for more than 90\%. Manufacturing is the third most significant step in the LCA. The remaining two LCA steps - disposal and transport. Transportation was found to be virtually negligible, even though the lamps in their packaging have traveled over 1800 kilometers from factory to home. 
Table 5 Life cycle assessment results of the LFL

\begin{tabular}{llllllll}
\hline LCA stages & ADP & AP & EP & GWP & RI & Waste Solids & Water Use \\
\hline Raw material & 0.0007731 & 0.06126 & 0.02637 & 9.47642 & 0.01347 & 3.11381 & 5.98919 \\
Manufacturing & 0.0000646 & 0.01434 & 0.01042 & 1.69615 & 0.00214 & 0.00000 & 0.02659 \\
Distribution & 0.0000025 & 0.00374 & 0.00062 & 0.35250 & 0.00071 & 0.00467 & 0.93011 \\
Use & 0.0004295 & 3.56614 & 0.23546 & 673.35772 & 1.04181 & 129.44671 & 2255.65224 \\
End of life & -0.0000038 & 0.00021 & 0.00527 & 0.89044 & 0.00004 & 0.00000 & 0.67491 \\
Total & 0.0012659 & 3.64569 & 0.27814 & 685.77323 & 1.05816 & 132.56519 & 2263.27305 \\
\hline
\end{tabular}

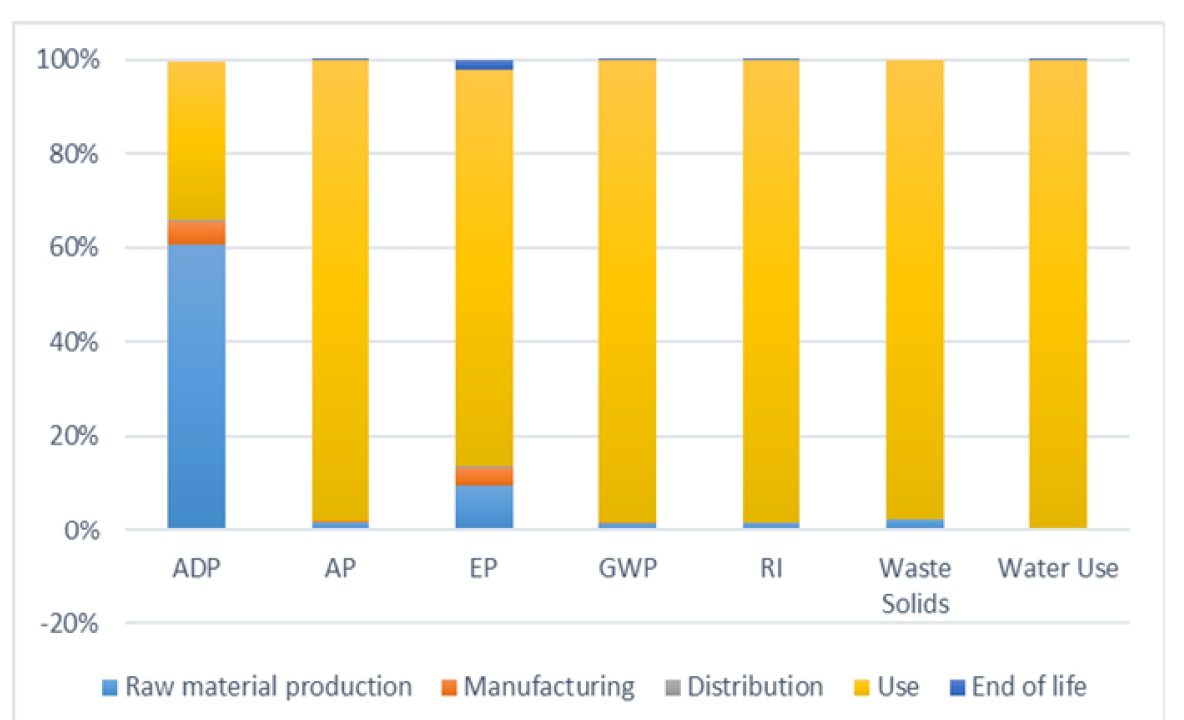

Fig. 3 Proportions of the life cycle assessment results for the LFL

For the LFL, as is shown in Table 5 and Fig. 3, the largest contributor to environmental impacts is energy, which represents at most $99 \%$ of the impact (for Water Use) and at least $35 \%$ (for ADP). The next most significant stage of the LCA is the raw materials, with ADP being the most impacted with $60 \%$ overall. Manufacturing is the third most impactful step in the LCA, with an impact of approximately 5\% in ADP and EP. The remaining two LCA steps - disposal and transport - constitute less than $1 \%$ respectively. As with the CFL, the impact associated with transport was found to be virtually negligible, even though the packaged CFLs travel over 1800 kilometers from factory to home.

Table 6 Life cycle assessment results of two lamps of the functional unit

\begin{tabular}{llllllll}
\hline Types & ADP & AP & EP & GWP & RI & Waste Solids & Water Use \\
\hline CFL & 0.15147 & 9.02242 & 4.82441 & 1167.14181 & 2.03667 & 185.06177 & 3239.08540 \\
LFL & 0.00127 & 3.64569 & 0.27814 & 685.77323 & 1.05816 & 132.56519 & 2263.27305 \\
\hline
\end{tabular}

The Table 6 presents the environmental impacts for each of the lamp types of the function unit. It is clearly that LFL has lower impacts than CFLs with the functional unit of 672 million lumen-hours of light. For both lamps, the greatest negative impact is in the use phase, when electricity for the running of the lamp is used. The impacts in distribution and disposal phase are insignificant. For GWP, the LFL lamp represents a $41 \%$ reduction over the CFL lamp for equivalent lighting service. For Water Use, the LFL offers a $30 \%$ reduction over the CFL. 


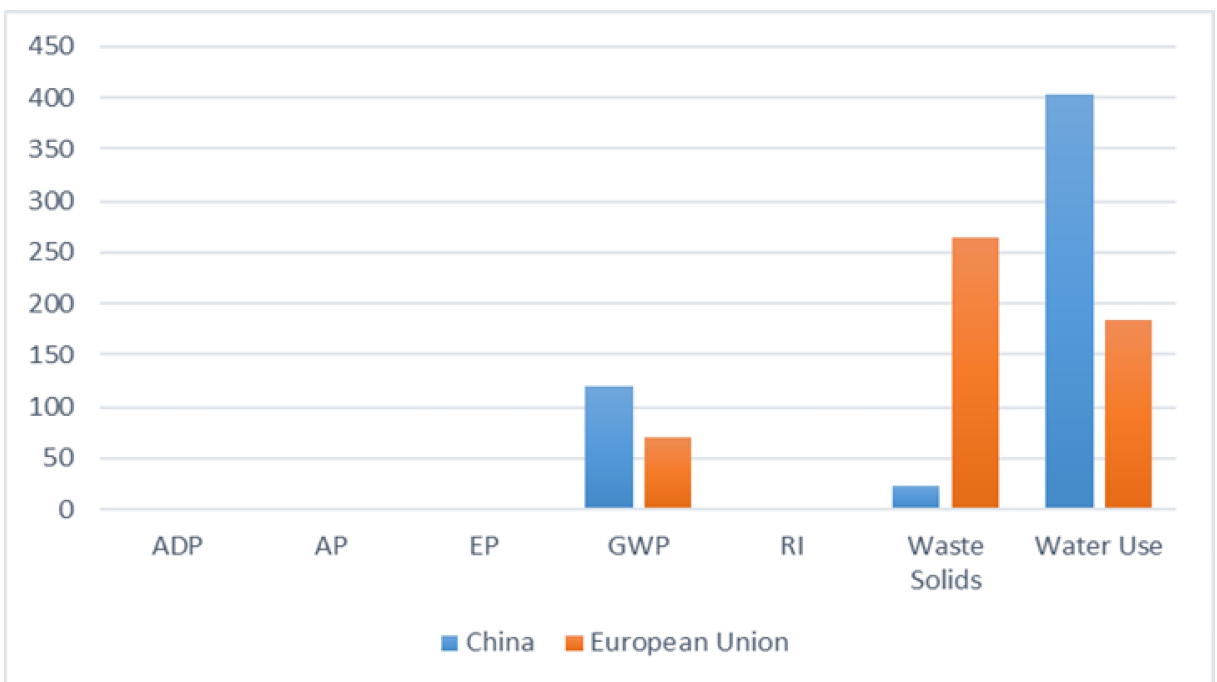

Fig. 4 Sensitivity analysis of use phase with China and EU electricity mix for the CFL

A sensitivity analysis has been performed on the use phase of the alternative lighting technologies by changing the Chinese electricity mix to average European electricity mix. As is shown in Fig. 4, when the use was modelled by using the European mix, the GWP during the use phase for a CFL are decreasing from $120.242 \mathrm{~kg} \mathrm{CO}_{2}$-eq to $70.850 \mathrm{~kg} \mathrm{CO}_{2}$-eq, decreasing by $41.10 \%$. While for the LFL, the GWP are changing from $673.358 \mathrm{CO}_{2}$-eq to $396.759 \mathrm{CO}_{2}$-eq, reducing by $41.08 \%$. However, the waste solids category in the European electricity mix has higher value than that in Chinese mix. It clearly indicates that with the change of electricity mix, the trends are similar across the two lighting technologies.

\section{Conclusions}

This study compared the environmental impacts of two lighting systems in China-compact fluorescent lamps and linear fluorescent lamps - throughout the life cycle. All the materials, energy use and pollutant emissions to the environment from each process were analyzed.

It was identified that the greatest negative impact of both kinds of lamps is in the use phase, when electricity for the running of the lamp is used. Impact caused by distribution can be neglected. The results showed that the disposal phase had nearly no impact from the total life cycle point of view. However, considering of cleaner energy production and mercury contained of FLs, the significance of disposal phase is increasing. Raw material production of CFLs is dominant in most of the categories, far more than LFL, especially in AP. CFLs have the comparable impacts with LFLs in the distribution phase. As for the use phase, the impacts of CFLs are 1.2 times higher than LFL in all of the categories. In general, LFL is a better source of the light from an environmental point of view than CFLs. It is expected the results can help policy makers and customers take informed decision.

\section{References}

[1] IEA. Light's labour's los. Policies for energy-efficient lighting. IEA, Paris. (2006)

[2] In Chinese. National Development and Reform Commission (NDRC). Roadmap on phasing-out of incandescent lamps in China, Beijing, China. (2011).

[3] Ramroth, L. Comparison of Life-Cycle Analyses of Compact Fluorescent and Incandescent Lamps Based on Rated Life of Compact Fluorescent Lamp., Rocky Mountain Institute. (2008)

[4] In Chinese. Ministry of Industry and Information Technology. Roadmap on gradually reducing mercury content of FLs. (2008) 
[5] Quirk, I. Life-Cycle Assessment and Policy Implications of Energy Efficient LightingTechnologies.(2009)http://nature.berkeley.edu/classes/es196/projects/2009final/QuirkI_ 2009.pdf.

[6] Osram. Executive Summary: Life Cycle Assessment of Illuminants - A Comparison of Light Bulbs, Compact Fluorescent Lamps and LED Lamps. (2009)

[7] Navigant Consulting Europe, Ltd. Life Cycle Assessment of Ultra-Efficient Lamps. (2009)

[8] US DOE. Life-cycle assessment of energy and environmental impacts of LED lighting products - part 2: LED manufacturing and performance. June 2012. US Department of Energy. (2012)

[9] ISO 14040. Environmental management-life cycle assessment-principles and framework. (2006)

[10] ISO 14044. Environmental management—life cycle assessment-requirements and guidelines. (2006)

[11] Quanyin Tan, Jinhui Li. A study of waste fluorescent lamp generation in mainland China. Journal of Cleaner Production. Vol.81(2014), p.227-233

[12] Eckelman MJ, Anastas PT, Zimmerman JB. Environ Sci Technol. Vol.42(2008), p.8564-8570. 